\title{
Retinal Melanoma
}

National Cancer Institute

\section{Source}

National Cancer Institute. Retinal Melanoma. NCI Thesaurus. Code C8601.

A melanoma affecting the retinal portion of the eye. --2003 